\title{
Impact of Eurycoma longifolia extract on DNA integrity, lipid peroxidation, and functional parameters in chilled and cryopreserved bull sperm
}

\begin{abstract}
This study aims to assess the effect of Eurycoma longifolia aqueous extract on chilled and cryopreserved quality of bull sperm. Semen samples were obtained from four SimmentalBrangus. Each sample was divided into two fractions: the first fraction was used for chilling the semen, and the second fraction was used for the freezing process. Both fractions were extended with Tris-egg yolk extender supplemented with $0.0,0.25,0.5,1.0,2.5,5.0$, and $7.5 \mathrm{mg} / \mathrm{ml}$ Eurycoma longifolia aqueous extract. The diluted chilled fraction was chilled at $5{ }^{\circ} \mathrm{C}$ for 6 days, whereas the frozen-thawed fraction was frozen in liquid nitrogen. Data revealed that $1 \mathrm{mg} / \mathrm{ml} \mathrm{E}$. longifolia aqueous extract yielded significantly $(\mathrm{p}<.05)$ higher sperm motility, morphology, viability, and sperm membrane integrity compared with the control group and other treated groups in chilled semen evaluation. For cryopreserved sperm, a significant difference $(\mathrm{p}<.05)$ in sperm motility, viability, sperm membrane integrity, DNA integrity, and lipid peroxidation was observed between $5 \mathrm{mg} / \mathrm{ml} \mathrm{E}$. longifolia aqueous extract and other treated and control groups. However, no significant difference in the percentage of sperm exhibiting normal sperm morphology was observed among the groups. In conclusion, the addition of 0.25 and $1 \mathrm{mg} / \mathrm{ml} \mathrm{E}$. langifolia extract to chilled semen and $5 \mathrm{mg} / \mathrm{ml} \mathrm{E}$. longifolia aqueous extract to cryopreserved sperm into Tris-egg yolk extender helps in maintaining superior quality of bull spermatozoa during chilling and freezing.
\end{abstract}

Keyword: Chilled semen; Cryopreserved sperm; Eurycoma longifolia; DNA integrity; Bull 